\title{
Morphological Investigation and Fractal Properties of Realgar Nanoparticles
}

\author{
Amir Lashgari, ${ }^{1}$ Shahriar Ghamami, ${ }^{1}$ Zahra Bahrami, ${ }^{1}$ Farzaneh Shomossi, \\ Guillermo Salgado-Morán, ${ }^{2}$ and Daniel Glossman-Mitnik ${ }^{3}$ \\ ${ }^{1}$ Department of Chemistry, Faculty of Science, Imam Khomeini International University, Qazvin 34148-96818, Iran \\ ${ }^{2}$ Departamento de Ciencias Químicas, Facultad de Ciencias Exactas, Universidad Andrés Bello, Sede Concepción, \\ 4070000 Concepción, Chile \\ ${ }^{3}$ Laboratorio Virtual NANOCOSMOS, Departamento de Medio Ambiente y Energía, \\ Centro de Investigación en Materiales Avanzados (CIMAV), 31136 Chihuahua, CHIH, Mexico
}

Correspondence should be addressed to Daniel Glossman-Mitnik; daniel.glossman@cimav.edu.mx

Received 1 March 2015; Revised 19 April 2015; Accepted 21 April 2015

Academic Editor: Xiaosheng Fang

Copyright (C) 2015 Amir Lashgari et al. This is an open access article distributed under the Creative Commons Attribution License, which permits unrestricted use, distribution, and reproduction in any medium, provided the original work is properly cited.

\begin{abstract}
Some arsenic compounds can show extraordinary polymorphism. Realgar $\left(\mathrm{As}_{4} \mathrm{~S}_{4}\right)$ is among several minerals with various crystal forms and is one of the most important sources of arsenic for pharmaceutical use. Currently, realgar is used as an arsenic source in many industries, such as weaponry, publishing, textiles, cosmetics, and health products. In this paper, we used and reported new methods for the purification, nanonization, and structural morphological investigations of $\mathrm{As}_{4} \mathrm{~S}_{4}$ by using planetary ball mills process for nanonization of the compound. The product was characterized using X-ray powder diffraction analysis, Fourier transform infrared spectrometry spectra, and field emission scanning electron microscope (FESEM) imaging. We investigated the morphological properties of FESEM-imaged realgar nanoparticles by an image-processing technique that calculates fractal dimensions using values on a computer with MATLAB software. We applied the Statistical Package for the Social Sciences software for statistics data extracted from the FESEM image and obtained the statistics results of the fractal dimension and histogram plot for the FESEM image.
\end{abstract}

\section{Introduction}

The anticancer action of arsenic compounds was reportedly discovered in Boston Hospital in 1878 , where the influence of Fowler's solution $\left(1 \% \mathrm{As}_{2} \mathrm{O}_{3}\right.$ in $\left.\mathrm{K}_{2} \mathrm{CO}_{3}\right)$ in reducing the number of white blood cells in leukemia patients was clinically defined [1]. Today, arsenic oxide $\mathrm{As}_{2} \mathrm{O}_{3}$ (under the brand name Trisenox) is widely applied for treating acute forms of leukemia [2-4]; however, its solubility is low and a certain type of pretreatment is required to enhance the solubility and/or to prepare nanosized particles with superior bioavailability and improved curative capacity [5].

Realgar is among the numerous minerals used for thousands of years in China as a medicine for treating anthrax, abdominal pains, children's convulsions, burning, and drying warts and treating abscesses and insect bites [6]; some reports indicate its use in treating CML and APL cancers as well [7]. Realgar has historically been used as a pigment. Realgar has a cage-like structure, with four arsenic atoms and four sulfur atoms, and can be found in veins and sublimation deposits in volcanic rocks, often found with gold, silver, and lead. The related mineral orpiment $\left(\mathrm{As}_{2} \mathrm{~S}_{3}\right)$ is also found in association with this mineral. Realgar, orpiment, and arsenopyrite are the principal ore minerals which provide for global arsenic demand [8]. In general, arsenic compounds are considered both toxic and pharmaceutical, depending on their chemical forms [9]. It is interesting to know that two factors, including molecular structure and dosage, determine either the pharmaceutical or toxic characteristics of arsenic [10].

In this paper, $\alpha$-realgar was investigated as a polymorph of realgar. The difference between $\alpha$ and $\beta \mathrm{As}_{4} \mathrm{~S}_{4}$ structures lies in their different molecular arrangement. The preparation 
of realgar was carried out by both traditional and modern methods, including acid extraction, membrane analysis, calcinations, various forms of milling (dry-, cryo-, and nanomilling), and chemical synthesis of particles by a stoichiometric As-S reaction [11].

Mechanochemistry can also be used to synthesize realgar because it can produce nanosized particles with improved solubility by a simple solid-state method [12-16]. As for mechanochemistry's application in pharmaceutical sciences, features such as bulk disordering, polymorphous transformations, and preparation of nanocrystalline powders via milling techniques have brought new impacts to pharmaceutical science [17-21]; here, the improved rate of dissolution and bioavailability plays a crucial role in the application of new drugs [22-25].

Image processing of nanostructures involves several preparation steps, separation, and postprocessing that finally lead to the extraction of quantitative data. Recently, computerbased image-processing methods have advanced rapidly, allowing quantification of complex colors, shapes, texture properties, and sizes. Image-processing methods are regularly used in tandem with mechanical and instrumental devices to change human manipulation in the display of an assumed process [26, 27].

Fractals are irregular forms with equal irregularities across all scales. The fractal dimension is a parameter for investigating the degree of data complexity and, in contrast to the naturally numbered Euclidian dimension, can be a real number [28]. The fractal geometry within the data may be calculated; exploration of the fractal dimension can lead to better investigation and prediction of the future behavior of data [29].

Various methods are used for estimating the fractal dimension. The box-counting method [30] is one of the simplest methods, which focuses on counting boxes in a straight line plot, where boxes with different lengths from $S$ and the number of boxes (tiles) are counted. If $N$ presents the obtained length in the $S$ scale, the fractal dimension can be calculated using the slope of the line in the log-log domain.

Our study presents descriptive data for the fractal dimension of $\mathrm{As}_{4} \mathrm{~S}_{4}$ nanoparticles. This method is basically a function in MATLAB (MathWorks, Natick, Massachusetts, USA), which is a powerful software package for drawing and analyzing data, programming, and performing engineering and research calculations [31-34]. Thus, we analyzed data from MATLAB with Statistical Package for the Social Sciences (SPSS; IBM, Armonk, New York, USA) software for discussing statistical aspects and give comparable results of our study.

\section{Experimental}

2.1. Materials and Methods. The starting materials were obtained from Merck (Berlin, Germany) and were used without further purification. Nanomaterials underwent spectrometry using a Fourier transform infrared (FT-IR) BrukerTensor 27 in the $400-4000 \mathrm{~cm}^{-1}$ range. The surface morphology of product was characterized by a field emission scanning electron microscope (FESEM) (Hitachi S 4160, Japan) with an accelerating voltage of $20 \mathrm{kV}$. X-ray powder diffraction (XRPD) measurements were performed using a Philips X'pert diffractometer (PANalytical, Almelo, the Netherlands) with monochromatized $\mathrm{CuK} \alpha$ radiation $(0.154 \mathrm{~nm})$. The sizes of the selected samples were estimated using the Scherer method. For identification, the FESEM samples were coated with gold.

2.2. Synthesis of $\mathrm{As}_{4} \mathrm{~S}_{4}$ Nanoparticles. First, $15 \mathrm{mg}$ of powdered realgar $\left(\mathrm{As}_{4} \mathrm{~S}_{4}\right)$ was added to $100 \mathrm{~mL}$ distilled water and the solution was boiled for 3 hours to remove soluble impurities. After three stages of filtration, and reduction of the $\mathrm{pH}$ to 5 by the addition of a few drops of $2 \mathrm{M} \mathrm{HCl}$, the remaining solid realgar was put in an oven for 10 hours at 80 degrees centigrade to dry. The dried compound was then transferred to one of the polymer jars of the planetary ball mills that contained 15 balls with different sizes for 5 hours of nanotreatment at room temperature (ball mill process).

2.3. Computational Method. Using MATLAB, 20 sections of the FESEM images of $\mathrm{As}_{4} \mathrm{~S}_{4}$ were selected and their fractal dimensions were calculated. The obtained fractal dimensions were fed into SPSS software to analyze the normal distribution, correlations, standard deviation, mean, cumulative frequency, and variance.

Considering the resulting numbers, we drew a logarithmic diagram in which the vertical and horizontal axes were $\log (1 / r)$ and $\log N_{r}$, respectively, and the coefficient of the box size was 1.3. We used a program written in MATLAB to calculate the fractal dimension. There are several methods for calculating the fractal definition, including (1) the selfsimilarly definition [35], (2) the mass fractal dimension [36], (3) the spare-sphere fractal dimension [37], (4) the Euclid dimension [38], (5) the grid style [39], (6) an analytical approach for fractal diminishing [40], and (7) the boxcounting fractal dimension [30].

We used the self-similar method for determining the fractal dimension from the FESEM image, which employed the box-counting method for the fractal dimension. Using the box-counting dimension method, we calculated the fractal's dimension theoretically by applying the following formula:

$$
D=\lim _{r \rightarrow 0} \frac{\log N_{r}}{\log (1 / r)},
$$

where $D$ is the fractal dimension and $N_{r}$ is the number of squares including a part of the considered fractal dimensions.

For the box-counting fractal dimension, we assumed that $F$ is a nonempty and bounded subset of $R^{n}$ and we supposed that $N_{r}(F)$ is the fewest number of collections with a maximum dimension of $(r)$ that can cover $(F)$. The boxcounting dimensions under and above $(F)$ : if they are equal we say they are equal to the box-counting dimension or the $F$ box dimension; then we define:

$$
\operatorname{dim}_{B} F=\lim _{r \rightarrow 0} \frac{\log N_{r}(F)}{-\log r} .
$$




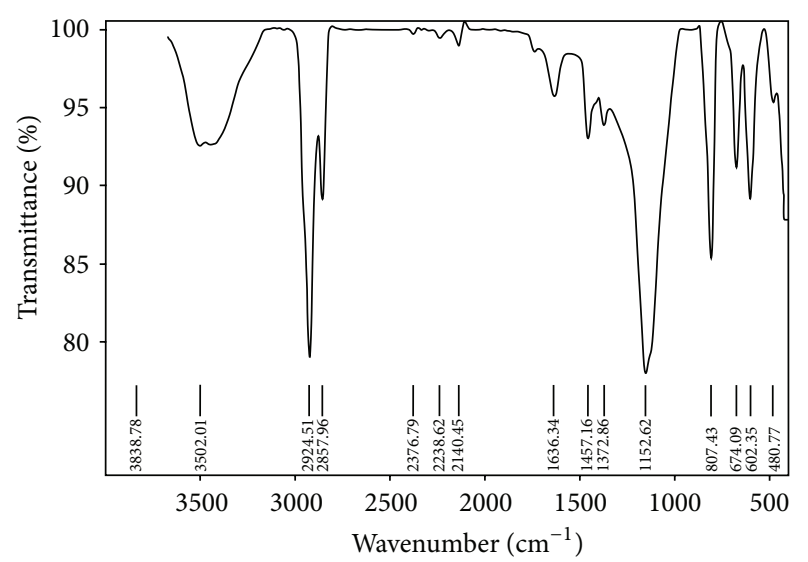

FIGURE 1: FT-IR spectrum of $\mathrm{As}_{4} \mathrm{~S}_{4}$ realgar compound measured by $\mathrm{KBr}$ technique.

The circle of cubes in $r$ coordinates from $R^{n}$ indicates cubes in the following form:

$$
\begin{gathered}
\text { If }\left[m_{1} r,\left(m_{1}+1\right) r\right] \times \cdots \times\left[m_{n} r,\left(m_{n}+1\right) r\right], \\
\text { Then } m_{n}, \ldots, m_{1} \text { are integers } \\
\text { Finally: } N_{r} \sqrt{n}(F) \leq N_{r}^{\prime}(F) \\
\text { If } r \sqrt{n}<1, \\
\text { Then } \frac{\log N_{r} \sqrt{n}(F)}{\log (r \sqrt{n})} \leq \frac{\log N_{r}^{\prime}(F)}{-\log \sqrt{n}-\log r} \\
\text { If we } \operatorname{limit} \operatorname{dim}_{B} F=\lim _{r \rightarrow 0} \frac{\log N_{r}^{\prime}(F)}{-\log r} \\
\text { Then } \overline{\operatorname{dim}_{B} F} \leq \varlimsup_{r \rightarrow 0} \frac{\log N_{r}^{\prime}(F)}{-\log r} \\
\text { Finally: } N_{r}^{\prime}(F) \leq 3^{n} N_{r}(F) .
\end{gathered}
$$

\section{Results and Discussions}

3.1. Interpretation of the FT-IR Spectrum of $A s_{4} S_{4}$ Nanoparticles. The FT-IR spectrum was taken within the 400$4000 \mathrm{~cm}^{-1}$ range to evaluate the purity of the synthesized realgar nanoparticles. Realgar is an inorganic compound and so lacks the spectral complexity of many organic materials and is without obvious factor groups. Upon adjusting the $\mathrm{pH}$, some acid and alkali were added to the solution, which caused absorption peaks; however, there were some impurities, and the widened peaks at $3500 \mathrm{~cm}^{-1}$ clearly show the included water (Figure 1). These spectra show the strong peaks at 2924 and $1152 \mathrm{~cm}^{-1}$ for the $\mathrm{C}-\mathrm{H}$ and $\mathrm{C}-\mathrm{O}$ vibrations that arose when acids and bases were added for $\mathrm{pH}$ adjustment [41].

The main spectrum at $481 \mathrm{~cm}^{-1}$ shows the As-S vibration, which confirms the realgar compound; many special vibrations for realgar are below $400 \mathrm{~cm}^{-1}$ and these vibrations do not appear in the spectra $[9,42]$.

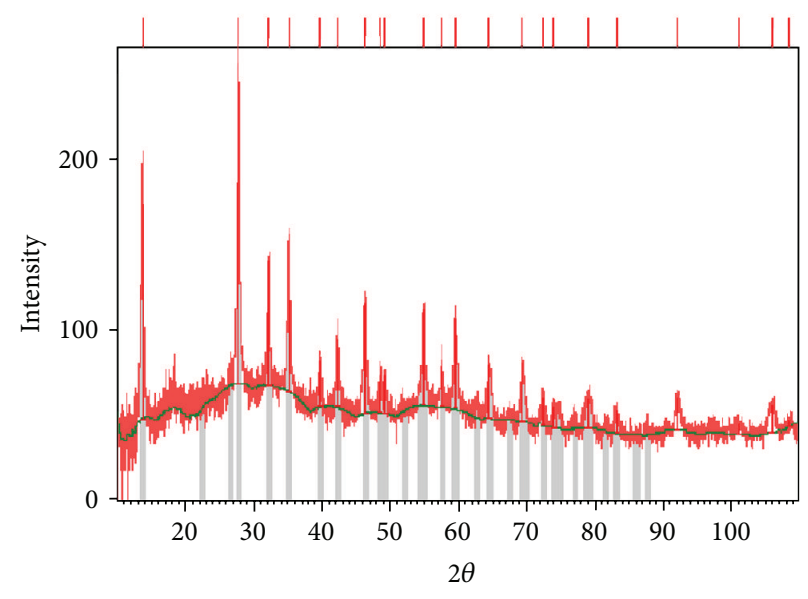

FIGURE 2: XRPD pattern of a realgar nanoparticle.

3.2. Variance X-Ray Powder Diffraction Analysis of $\mathrm{As}_{4} \mathrm{~S}_{4}$ Realgar Nanoparticles. To obtain the crystallite size distribution of the particles by the half-height method, an FWHM XRPD pattern was used (Figure 2). As observed, the XRPD pattern presents maximum intensity peaks, indicating the small sizes of crystals in the samples synthesized. To obtain the particle size and the peak width by the half-height of FWHM, we applied the Debye-Scherrer equation to get the approximate crystallite sizes of the particles:

$$
D(\mathrm{~nm})=\frac{K \lambda}{\beta \cos \theta}
$$

where $D$ is particle size by $\mathrm{nm} ; \mathrm{K}$ is constant equivalent to $0.99 ; \lambda$ is wavelength of $\mathrm{CuK} \alpha$ (equivalent to $0.154 \mathrm{~nm}$ ); $\beta$ is peak width by half height; and $\theta$ is variance angle by degrees:

$$
\begin{aligned}
\text { FWHM } & =0.0984, \\
\beta & =0.001717, \\
2 \theta & =27.8932, \\
\theta & =13.9466^{\circ}, \\
\cos \theta & =0.9705, \\
D & =\frac{0.99 \times 0.154}{0.001717 \times 0.9705}, \\
D & =91.49 \mathrm{~nm} .
\end{aligned}
$$

The particle size was calculated by the Debye-Scherrer Equation and revealed that the particle size of the maximum FWHM (0.0984) was around $91 \mathrm{~nm}$.

3.3. Morphological Properties. The image of the surface and morphological structure of the sample indicates that the realgar nanopowder obtained was condensed and highly porous and was comprised of $20 \mathrm{~nm}$ spherical particles; larger particles observed in the surface of the image were formed as a result of the aggregation of the smaller particles, which manifested as irregular spherical shapes. FESEM images of the realgar nanoparticles are shown in Figure 3. 

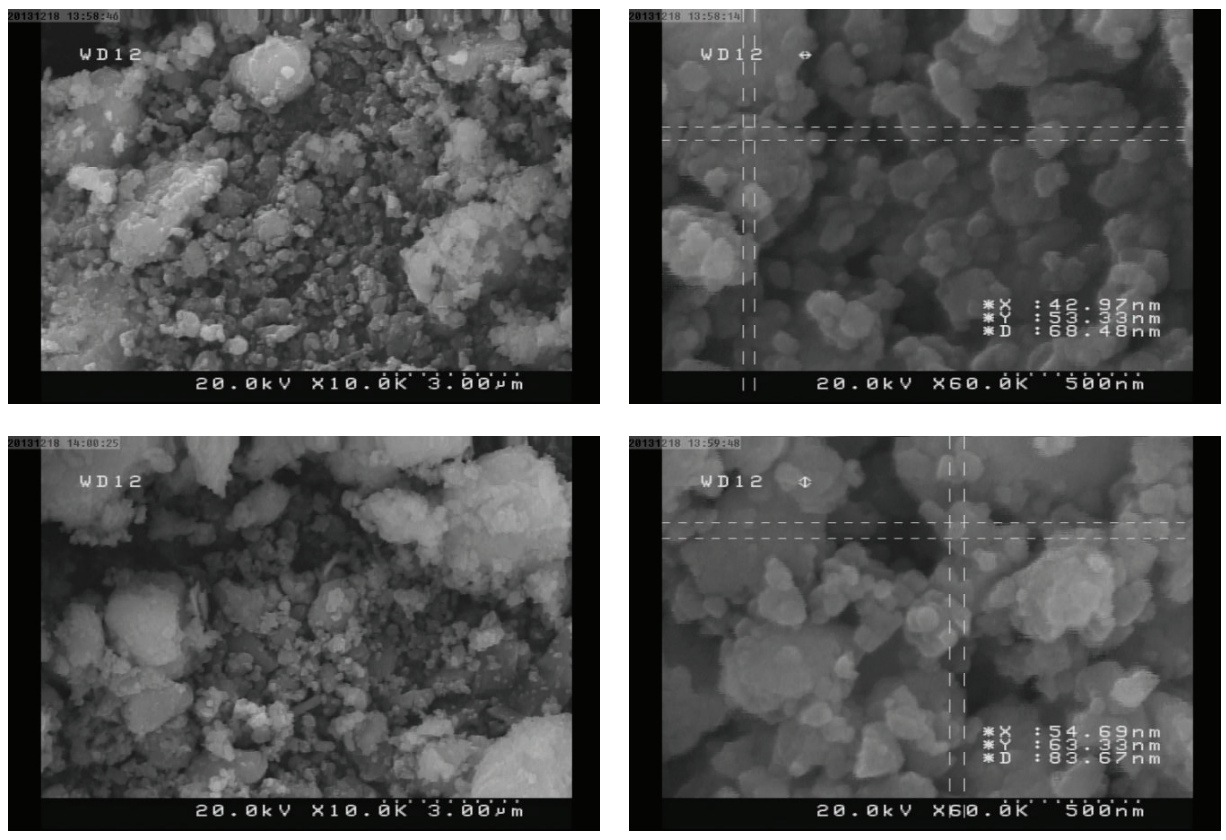

FIGURE 3: FESEM images of realgar nanoparticles.

\subsection{Fractal Properties}

3.4.1. General. For analyzing fractals in MATLAB, FESEM images are required. In the present research, FESEM images were used for imaging particle surfaces to determine the fractal dimension. Having used MATLAB for determining the fractal dimension of realgar, SPSS software was used to analyze the MATLAB data. SPSS can determine the frequency of groups in one variable, calculate a simple mean for data, prepare data for testing the relationships between variables, calculate correlations, perform multivariate regressions, and analyze diagnostic functions, linear logarithms, and other multivariate logarithms. In the present research, other characteristics, such as statistical analyses, normality tests, correlation of variables, cumulative frequency, standard deviation, variance, mean, and harmonic mean, were extracted in SPSS.

3.4.2. Analysis of MATLAB and SPSS Data. The descriptive statistics of the fractal dimension are listed in Table 1 . This table shows the fractal dimensions of 20 random, separated pieces of the FESEM image with frequency and the valid and cumulative percent of each piece. When dealing with statistical information, we come through numbers, which are sometimes repeated; after the similar value appears more than once, it is recognized as the frequency of a number. The total frequency of all modules less than the higher class boundary of a quantified class is named the cumulative frequency of that class. Cumulative frequency is found by addition of a class interval to the frequency and the frequencies of the former intervals up to that class interval. This is another way of expressing frequency distribution. Cumulative frequency was used to determine the number of explanations that were below or above a specific value. The highest advantage of
TABLE 1: Statistics of $\mathrm{As}_{4} \mathrm{~S}_{4}$ nanoparticles in the fractal dimension.

\begin{tabular}{lcccc}
\hline Valid & Frequency & Percent & Valid percent & Cumulative percent \\
\hline 1.32 & 1 & 5.0 & 5.0 & 5.0 \\
1.35 & 1 & 5.0 & 5.0 & 10.0 \\
1.39 & 1 & 5.0 & 5.0 & 15.0 \\
1.43 & 1 & 5.0 & 5.0 & 20.0 \\
1.48 & 1 & 5.0 & 5.0 & 25.0 \\
1.49 & 1 & 5.0 & 5.0 & 30.0 \\
1.51 & 2 & 10.0 & 10.0 & 40.0 \\
1.54 & 1 & 5.0 & 5.0 & 45.0 \\
1.57 & 2 & 10.0 & 10.0 & 55.0 \\
1.58 & 2 & 10.0 & 10.0 & 65.0 \\
1.62 & 2 & 10.0 & 10.0 & 75.0 \\
1.69 & 1 & 5.0 & 5.0 & 80.0 \\
1.73 & 2 & 10.0 & 10.0 & 90.0 \\
1.74 & 1 & 5.0 & 5.0 & 95.0 \\
1.78 & 1 & 5.0 & 5.0 & 100.0 \\
\hline Total & 20 & 100.0 & 100.0 & - \\
\hline
\end{tabular}

using cumulative percentage is that it offers an easier method to compare different sets of data.

In statistics and probability theory, skewness reflects the degree of asymmetry of the probability distribution. Skewness is a measure of the presence or absence of distribution function symmetry: for a perfectly symmetrical distribution, the skewness is zero; for an asymmetric distribution with stretching toward higher quantities, the skewness is positive; and for an asymmetric distribution with stretching toward smaller quantities, the skewness is negative. Considering Table 2, we observed the skewness to be -2.178 , which 
TABLE 2: Statistical values of the selected $\mathrm{As}_{4} \mathrm{~S}_{4}$ nanoparticles.

\begin{tabular}{lccccccc}
\hline Total counts & Range & Minimum & Maximum & Mean & Variance & Skewness & Kurtosis \\
\hline 20 & 0.94 & 0.84 & 1.78 & 1.5375 & 0.041 & -2.178 & 7.090 \\
\hline
\end{tabular}

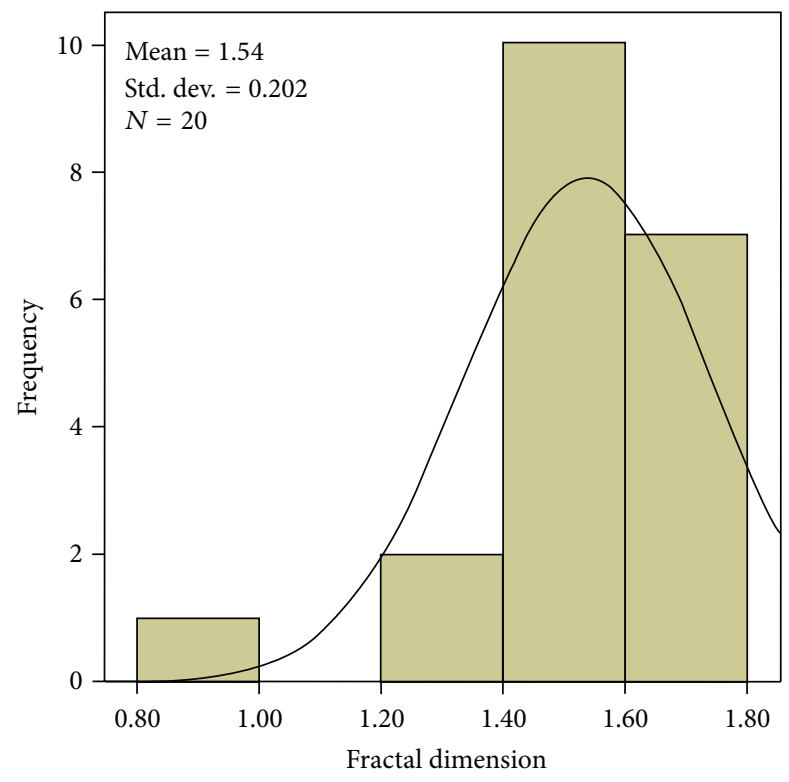

FIgURE 4: Histogram plot of selected $\mathrm{As}_{4} \mathrm{~S}_{4}$ nanoparticles.

indicates an asymmetric distribution; because the obtained figure is negative, the asymmetry is skewed towards smaller values.

A grayscale digital image is collected from separate points of gray tones, or brightness, before incessantly variable tones. A normal image is separated into a number of specific points of brightness, and each of those points is defined via a digital data value. A pixel is the greatest elementary element of a digital image; each brightness point is a pixel of the digital image. Essentially, the image histogram shows the distribution of the pixel intensities in the image and those continuously used as a reference. Interactive thresholding can be very effective and afford fast, precise information $[43,44]$. The histogram plot extracted with SPSS software is given in Figure 4.

3.4.3. Model Description. In the obtained sections of $\mathrm{As}_{4} \mathrm{~S}_{4}$ nanoparticles, the minimum and maximum fractal dimensions were 0.84 and 1.78 , respectively; the mean fractal dimension was 1.53 (in statistics, mean signifies central tendency). The normal and detrended normal P-P and Q-Q correlations are plotted in Figure 5. It was observed that the distribution of the fractal dimensions of the $\mathrm{As}_{4} \mathrm{~S}_{4}$ nanoparticles was aligned in a straight line, and the hypothesis of a normal distribution of errors was true. The drawing normal and detrended normal P-P and Q-Q plots for residuals are fitted here. If the fitted model is appropriate, the figure must be symmetric, and the points must be scattered consistently; this indicates a fixed variance of errors, which is optimal in nature. Summarizing all these data can help us determine the fractal characteristics (Figure 5).

Correlations are associated with value and direction, like a vector: its value indicates the degree of relationship between two variables, and its direction indicates the direction of behavior (either same direction or the opposite) of the variables under investigation. It is a statistic for measuring the power of degree of the linear relationship between several variables and can range from +1 to -1 . Values close to +1 and -1 show strong correlation (either positive or negative); however, the more they approach zero, the less powerful the correlation will be. In SPSS, one of the correlation coefficients can be used to determine the degree and type of relationships, based on the type and nature of variables. In the present paper, we used the Pearson correlation coefficient, which is applicable to quantitative variables.

Where continuous variables are considered in normal distributions, this equation is strongly affected by sample size. Therefore, we investigated more points to ensure that we applied a powerful test. The Pearson correlation coefficient is based on the covariance and deviations of the variables, where their estimations can be used for calculating the Pearson correlation coefficient. Also, as Table 3 indicates, the correlation of the fractal dimension of nanoparticles of $\mathrm{As}_{4} \mathrm{~S}_{4}$ is 0.994; this indicates a strong positive correlation between the variables. The obtained coefficient indicates a strong relationship between the different sections of the image, which all confirm that this mineral is highly fractal. In short, an extremely complex order can be observed in an irregular and disordered appearance. 

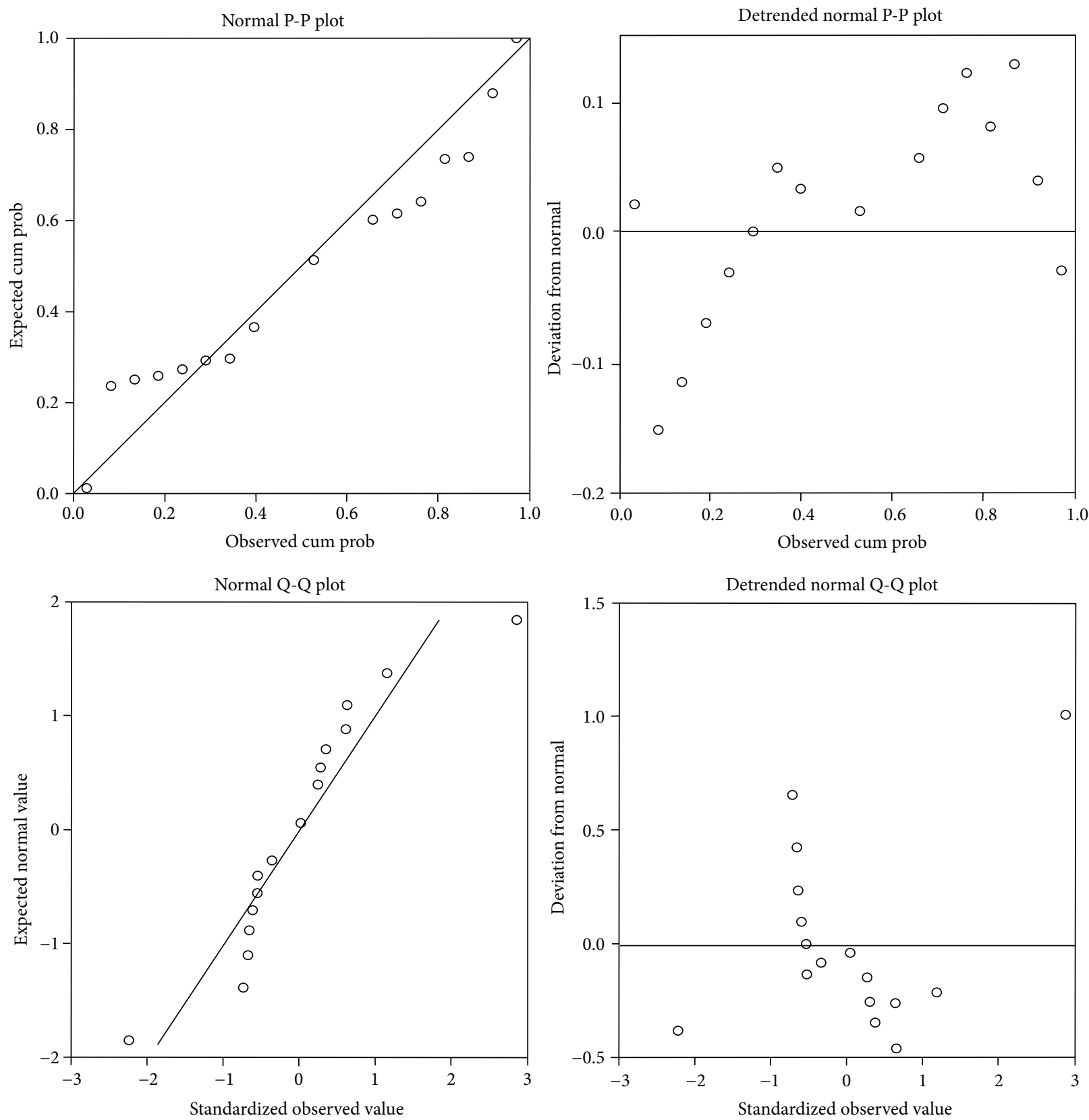

FIgURE 5: Normal and detrended normal P-P and Q-Q plots.

\section{Conclusions}

New methods for the purification, nanonization, and structural and morphological investigations of $\mathrm{As}_{4} \mathrm{~S}_{4}$, using a planetary ball mills for nanonization of the realgar compound, were reported. The realgar nanoparticles experimentally characterized by using XRPD analysis, FT-IR spectra and FESEM image analysis, and the obtained FESEM images were used for investigate the phase composition, morphological, and fractal dimension calculations by MATLAB and SPSS software. The image of the surface and morphological structure of the sample indicates that the obtained nanopowder was condensed. We conclude that the calculation of the fractal dimensions of the FESEM images of 20 randomly selected particles of the nanomaterial and calculation of the Max, Min, and many other data can be used for the analysis of nanoparticles; therefore, homogeneity and uniformity were considered. The correlation of the fractal dimension of the nanoparticles of $\mathrm{As}_{4} \mathrm{~S}_{4}$ gave a value of 0.994 , which indicates a strong positive correlation between the variables.

The realgar nanoparticles are planned for use in patients with gastric cancer, since it can alleviate pain for a while; it will not be used in trials with healthy individuals because of the highly toxic nature of inorganic arsenic compounds. Finally, investigating the use of this compound for therapeutic purposes will be considered by oncologists. 
TABLE 3: Correlation of the fractal dimension of nanoparticles.

\begin{tabular}{lccc}
\hline \multicolumn{2}{c}{ Correlations } & & \\
& & Fractal & Dimension \\
\hline \multirow{4}{*}{ Fractal } & Pearson correlation & 1 & 0.994 \\
& Sig. (2-tailed) & - & 0.457 \\
& Sum of squares and & 0.392 & 0.047 \\
& cross products & & \\
& Covariance & 0.049 & 0.006 \\
& $N$ & 9 & 9 \\
\hline \multirow{4}{*}{ Dimension } & Pearson correlation & 0.994 & 1 \\
& Sig. (2-tailed) & 0.457 & - \\
& Sum of squares and & 0.047 & 0.070 \\
& Coss products & 0.006 & 0.008 \\
& $\quad$ Covariance & 9 & 10 \\
\hline
\end{tabular}

\section{Conflict of Interests}

The authors declare that there is no conflict of interests regarding the publication of this paper.

\section{Acknowledgments}

The authors gratefully acknowledge the financial support from the Research Council of Imam Khomeini International University. Daniel Glossman-Mitnik is a researcher of CONACYT and CIMAV and acknowledges partial support from both institutions.

\section{References}

[1] P. J. Dilda and P. J. Hogg, "Arsenical-based cancer drugs," Cancer Treatment Reviews, vol. 33, no. 6, pp. 542-564, 2007.

[2] W. H. Miller Jr., H. M. Schipper, J. S. Lee, J. Singer, and S. Waxman, "Mechanisms of action of arsenic trioxide," Cancer Research, vol. 62, no. 14, pp. 3893-3903, 2002.

[3] R. A. Campbell, E. Sanchez, J. A. Steinberg et al., "Antimyeloma effects of arsenic trioxide are enhanced by melphalan, bortezomib and ascorbic acid," British Journal of Haematology, vol. 138, no. 4, pp. 467-478, 2007.

[4] L. Wang, G.-B. Zhou, P. Liu et al., "Dissection of mechanisms of Chinese medicinal formula Realgar-Indigo naturalis as an effective treatment for promyelocytic leukemia," Proceedings of the National Academy of Sciences of the United States of America, vol. 105, no. 12, pp. 4826-4831, 2008.

[5] J. Zhang, X. Zhang, Y. Ni, X. Yang, and H. Li, "Bioleaching of arsenic from medicinal realgar by pure and mixed cultures," Process Biochemistry, vol. 42, no. 9, pp. 1265-1271, 2007.

[6] Y.-F. Lu, J.-W. Yan, Q. Wu, J.-Z. Shi, J. Liu, and J.-S. Shi, "Realgarand cinnabar-containing An-Gong-Niu-Huang Wan (AGNH) is much less acutely toxic than sodium arsenite and mercuric chloride," Chemico-Biological Interactions, vol. 189, no. 1-2, pp. 134-140, 2011.

[7] H. A. Bullen, M. J. Dorko, J. K. Oman, and S. J. Garrett, "Valence and core-level binding energy shifts in realgar $\left(\mathrm{As}_{4} \mathrm{~S}_{4}\right)$ and pararealgar $\left(\mathrm{As}_{4} \mathrm{~S}_{4}\right)$ arsenic sulfides," Surface Science, vol. 531, no. 3 , pp. 319-328, 2003.
[8] R. Simon and R. E. Wittes, "Methodologic guidelines for reports of clinical trials," Cancer Treatment Reports, vol. 69, no. 1, pp. 13, 1985.

[9] A. Banerjee, J. O. Jensen, and J. L. Jensen, "A theoretical study of $\mathrm{As}_{4} \mathrm{~S}_{4}$ : bonding, vibrational analysis and infrared and raman spectra," Journal of Molecular Structure: THEOCHEM, vol. 626, pp. 63-75, 2003.

[10] J. Wu, Y. Shao, J. Liu, G. Chen, and P. C. Ho, "The medicinal use of realgar $\left(\mathrm{As}_{4} \mathrm{~S}_{4}\right)$ and its recent development as an anticancer agent," Journal of Ethnopharmacology, vol. 135, no. 3, pp. 595602, 2011.

[11] P. Bonazzi, S. Menchetti, and G. Pratesi, "The crystal structure of pararealgar, $\mathrm{As}_{4} \mathrm{~S}_{4}$," American Mineralogist, vol. 80, no. 3-4, pp. 400-403, 1995.

[12] V. V. Boldyrev, "Mechanical activation and its application totechnology," Journal de Chimie Physique, vol. 83, pp. 821-829, 1986.

[13] P. Baláž, Extractive Metallurgy of Activated Minerals, Elsevier, Amsterdam, The Netherlands, 2000.

[14] P. Baláž, "Mechanochemistry of sulphides," Journal of Materials Science, vol. 39, no. 16-17, pp. 5097-5102, 2004.

[15] P. Baláž, W. S. Choi, and E. Dutková, "Mechanochemical modification of properties and reactivity of nanosized arsenic sulphide $\mathrm{As}_{4} \mathrm{~S}_{4}$," Journal of Physics and Chemistry of Solids, vol. 68, no. 5-6, pp. 1178-1183, 2007.

[16] P. Baláž, Mechanochemistry in Nanoscience and Minerals Engineering, Springer, Berlin, Germany, 2008.

[17] T. P. Shakhtshneider, "Phase transformations and stabilization of metastable states of molecular crystals under mechanical activation," Solid State Ionics, vol. 101-103, no. 1, pp. 851-856, 1997.

[18] V. V. Boldyrev, "Mechanochemical modification and synthesis of drugs," Journal of Materials Science, vol. 39, no. 16-17, pp. 51175120,2004

[19] P. Baláž, M. Achimovičová, M. Baláž et al., "Hallmarks of mechanochemistry: from nanoparticles to technology," Chemical Society Reviews, vol. 42, no. 18, pp. 7571-7637, 2013.

[20] I. Colombo, G. Grassi, and M. Grassi, "Drug mechanochemical activation," Journal of Pharmaceutical Sciences, vol. 98, no. 11, pp. 3961-3986, 2009.

[21] T. Friščić, "New opportunities for materials synthesis using mechanochemistry," Journal of Materials Chemistry, vol. 20, no. 36, pp. 7599-7605, 2010.

[22] J.-Z. Wu and P. C. Ho, "Evaluation of the in vitro activity and in vivo bioavailability of realgar nanoparticles prepared by cryogrinding," European Journal of Pharmaceutical Sciences, vol. 29, no. 1, pp. 35-44, 2006.

[23] P. Baláž, M. Fabián, M. Pastorek, D. Cholujová, and J. Sedlák, "Mechanochemical preparation and anticancer effect of realgar $\mathrm{As}_{4} \mathrm{~S}_{4}$ nanoparticles," Materials Letters, vol. 63, no. 17, pp. 15421544, 2009.

[24] P. Baláž and J. Sedlák, "Arsenic in cancer treatment: challenges for application of realgar nanoparticles (a minireview)," Toxins, vol. 2, no. 6, pp. 1568-1581, 2010.

[25] P. Baláž, M. Fabián, M. Pastorek, D. Cholujová, and J. Sedlák, "Anticancer effects ofrealgar $\mathrm{As}_{4} \mathrm{~S}_{4}$ particles prepared by nanomilling," in Arsenic in Geosphere and Human Diseases, Tainan, J. S. Jean, J. Bundschuh, and P. Bhattacharya, Eds., pp. 350-351, Taylor \& Francis, London, UK, 2010.

[26] Q. Z. Li, M. H. Wang, and W. K. Gu, "Computer vision based system for apple surface defect detection," Computers and Electronics in Agriculture, vol. 36, no. 2-3, pp. 215-223, 2002. 
[27] A. Hosseini, S. M. Jafari, H. Mirzaei, A. Asghari, and S. Akhavan, "Application of image processing to assess emulsion stability and emulsification properties of Arabic gum," Carbohydrate Polymers, vol. 126, pp. 1-8, 2015.

[28] A. Turiel and A. del Pozo, "Reconstructing images from their most singular fractal manifold," IEEE Transactions on Image Processing, vol. 11, no. 4, pp. 345-350, 2002.

[29] M. F. Barnsley and A. Jacquin, "Application of recurrent iterated function systems to images," in Visual Communications and Image Processing '88: Third in a Series, vol. 1001 of Proceedings of SPIE, pp. 122-131, October 1988.

[30] M. K. Biswas, T. Ghose, S. Guha, and P. K. Biswas, "Fractal dimension estimation for texture images: a parallel approach," Pattern Recognition Letters, vol. 19, no. 3-4, pp. 309-313, 1998.

[31] D. G. Altman, "Statistics in medical journals," Statistics in Medicine, vol. 1, no. 1, pp. 59-71, 1982.

[32] J. R. O'Fallon, S. D. Dubey, and D. S. Salsburg, "Should there be statistical guidelines for medical research papers?" Biometrics, vol. 34, no. 4, pp. 687-695, 1978.

[33] J. C. Bailar III and F. Mosteller, "Guidelines for statistical reporting in articles for medical journals. Amplifications and explanations," Annals of Internal Medicine, vol. 108, no. 2, pp. 266-273, 1988.

[34] M. J. Lichtenstein, C. D. Mulrow, and P. C. Elwood, "Guidelines for reading case-control studies," Journal of Chronic Diseases, vol. 40, no. 9, pp. 893-903, 1987.

[35] B. Mandelbrot, "How long is the coast of Britain? Statistical selfsimilarity and fractional dimension," Science, vol. 156, no. 3775 , pp. 636-638, 1967.

[36] E. Perfect, "Estimating soil mass fractal dimensions from water retention curves," Geoderma, vol. 88, no. 3-4, pp. 221-231, 1999.

[37] M. Borkovec, W. de Paris, and R. Peikert, "The fractal dimension of the Apollonian sphere packing," Fractals, vol. 2, no. 4, pp. 521$526,1994$.

[38] Z. Khanbabaei, A. Karam, and G. Rostamizad, "Studying relationships between the fractal dimension of the drainage basins and some of their geomorphological characteristics," International Journal of Geosciences, vol. 4, no. 3, pp. 636-642, 2013.

[39] P. Parsons-Wingerter, B. Lwai, M. C. Yang et al., "A novel assay of angiogenesis in the quail chorioallantoic membrane: stimulation by bFGF and inhibition by angiostatin according to fractal dimension and grid intersection," Microvascular Research, vol. 55, no. 3, pp. 201-214, 1998.

[40] E. Guérin and E. Tosan, "Fractal inverse problem: approximation formulation and differential methods," Fractals in Engineering, pp. 271-285, 2005.

[41] R. M. Silverstein, G. C. Bassler, and T. C. Morrill, Spectrometric Identification of Organic Compounds, John Wiley \& Sons, New York, NY, USA, 4th edition, 1981.

[42] M. Muniz-Miranda, G. Sbrana, P. Bonazzi, S. Menchetti, and G. Pratesi, "Spectroscopic investigation and normal mode analysis of $\mathrm{As}_{4} \mathrm{~S}_{4}$ polymorphs," Spectrochimica Acta Part A: Molecular Spectroscopy, vol. 52, no. 11, pp. 1391-1401, 1996.

[43] G. F. Voort, "Metallography and Microstructures," in ASM Handbook, vol. 9, ASM International, Materials Park, Ohio, USA, 2004.

[44] L. Wojnar, Image Analysis, Applications in Materials Engineering, CRC Press, Boca Raton, Fla, USA, 1999. 

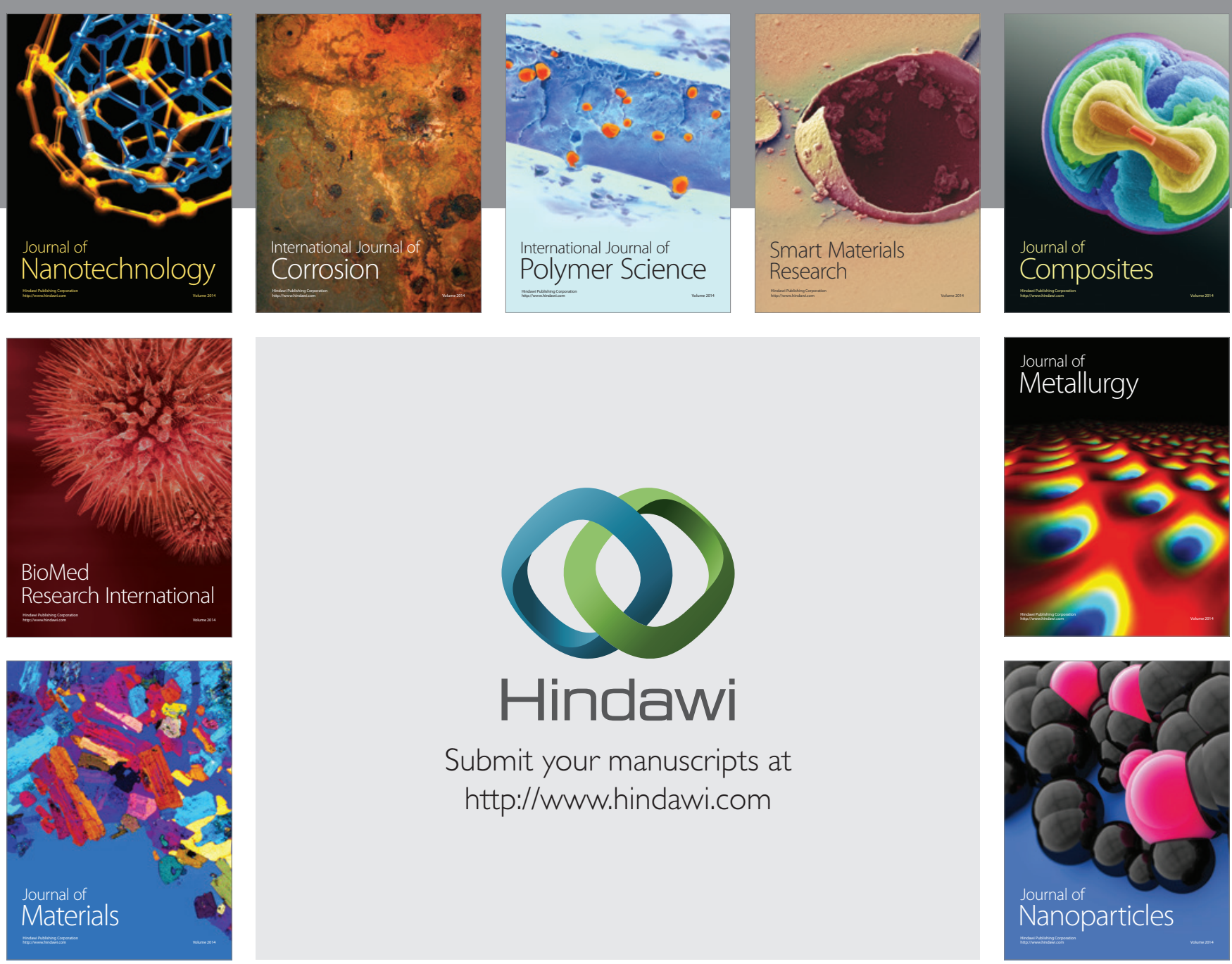

Submit your manuscripts at http://www.hindawi.com
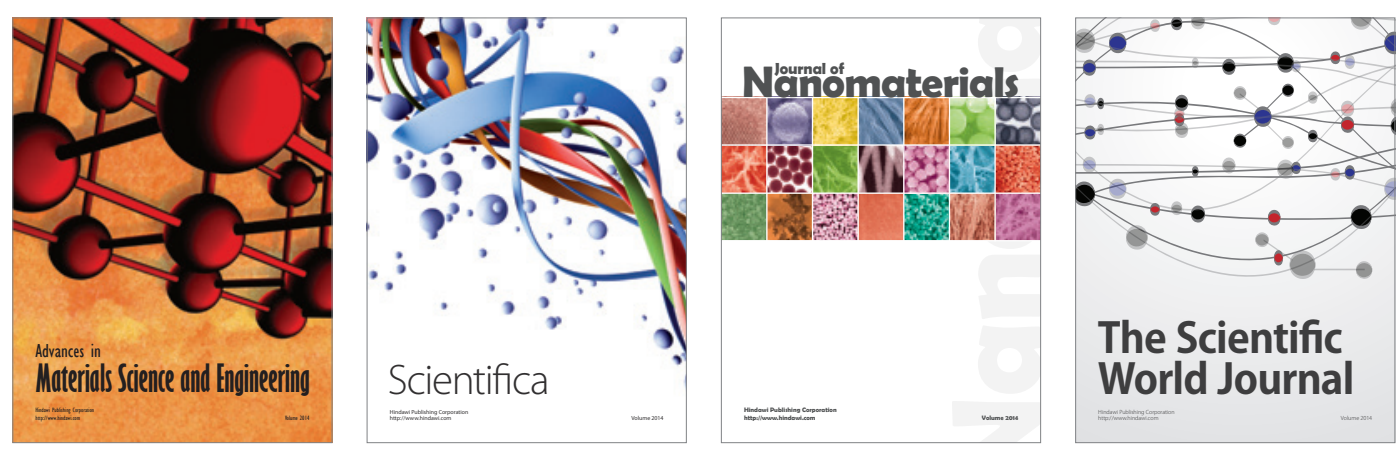

\section{The Scientific World Journal}
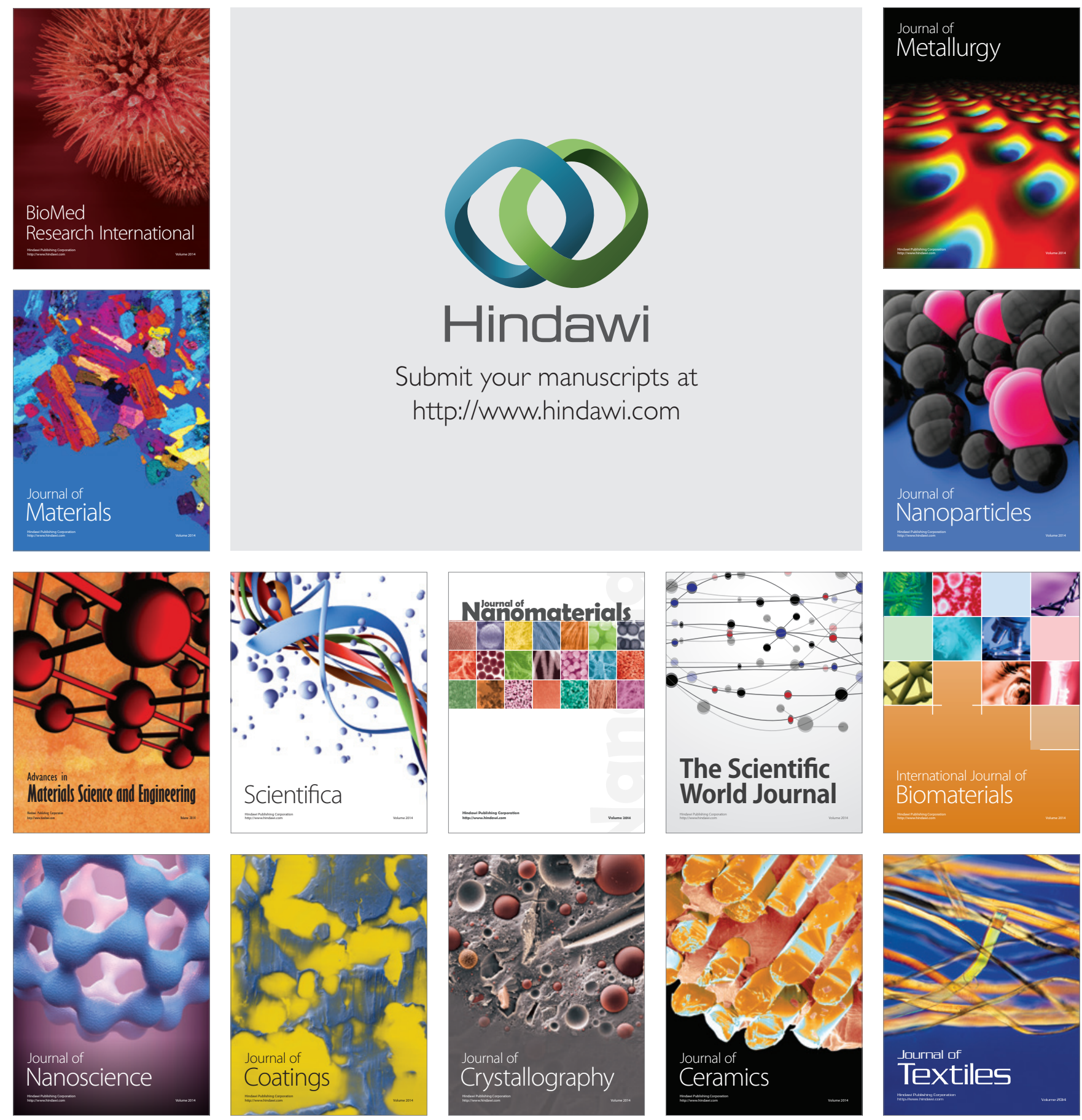